\title{
Descrição dos estágios imaturos e redescrição de Lamprosoma azureum Germar (Chrysomelidae, Lamprosomatinae) ${ }^{1}$
}

\author{
Marcelo Galeazzi Caxambú ${ }^{2}$ \\ Lúcia Massutti de Almeida ${ }^{2}$
}

\begin{abstract}
Description of the immature stages and redescription of Lamprosoma azureum Germar (Chrysomelidae, Lamprosomatinae). A morphological study of the adult and the immature stages of Lamprosoma azureum Germar, 1824 is presented. The immature stages are described for the first time. Morphological information is discussed and new data included. The immature stages of Lamprosoma azureum are compared with those of $L$. bicolor Kirby, $1818, L$. chorisiae Monrós, 1948, Oomorphoides cupreatus Baly, 1873 and O. nigrocoerulus Baly, 1873.

KEY WORDS. Chrysomelidae, Lamprosoma azureum, morphology, immature stages, adult
\end{abstract}

Os Lamprosomatinae têm sido muito pouco estudados sob o ponto de vista taxonômico e morfológico. O gênero Lamprosoma Kirby, 1818 possui cerca de 130 espécies, sendo 54 assinaladas para o Brasil. Os principais trabalhos realizados foram os de CHAPUIS (1874) e MONRós (1948-60). Este autor em 1956 contribuiu com o principal trabalho para o conhecimento dos Lamprosomatinae, definindo a subfamília e apresentando chaves para identificação, além da descrição de alguns gêneros e espécies novas.

MOREIRA (1913) estudou a morfologia das formas imaturas de Lamprosoma bicolor Kirby, 1818 e MonRós (1949) trabalhou com a morfologia das formas imaturas e aspectos bioecológicos de Lamprosoma chorisiae Monrós, 1948.

Larvas e adultos de Lamprosoma azureum Germar, 1824 têm sido encontrados alimentando-se de espécies de Myrtaceae e Melastomataceae, causando danos significativos a estas plantas. O araçazeiro, espécie nativa do Brasil, foi introduzido no arquipélago do Havaí em 1825 e tornou-se uma planta indesejável, uma vez que tem invadido áreas de parques, deslocando a flora nativa e causando problemas de ordem econômica.

Este trabalho visa coletar informações básicas sobre o inseto e, através da morfologia das formas imaturas e do adulto, contribuir para seu conhecimento e possível utilização como um agente de controle biológico do araçazeiro.

1) Contribuição número 1107 do Departamento de Zoologia, Universidade Federal do Paraná.

2) Departamento de Zoologia, Universidade Federal do Paraná. Caixa Postal 19020, 81531-990 Curitiba, Paraná, Brasil. Bolsista do CNPq. 

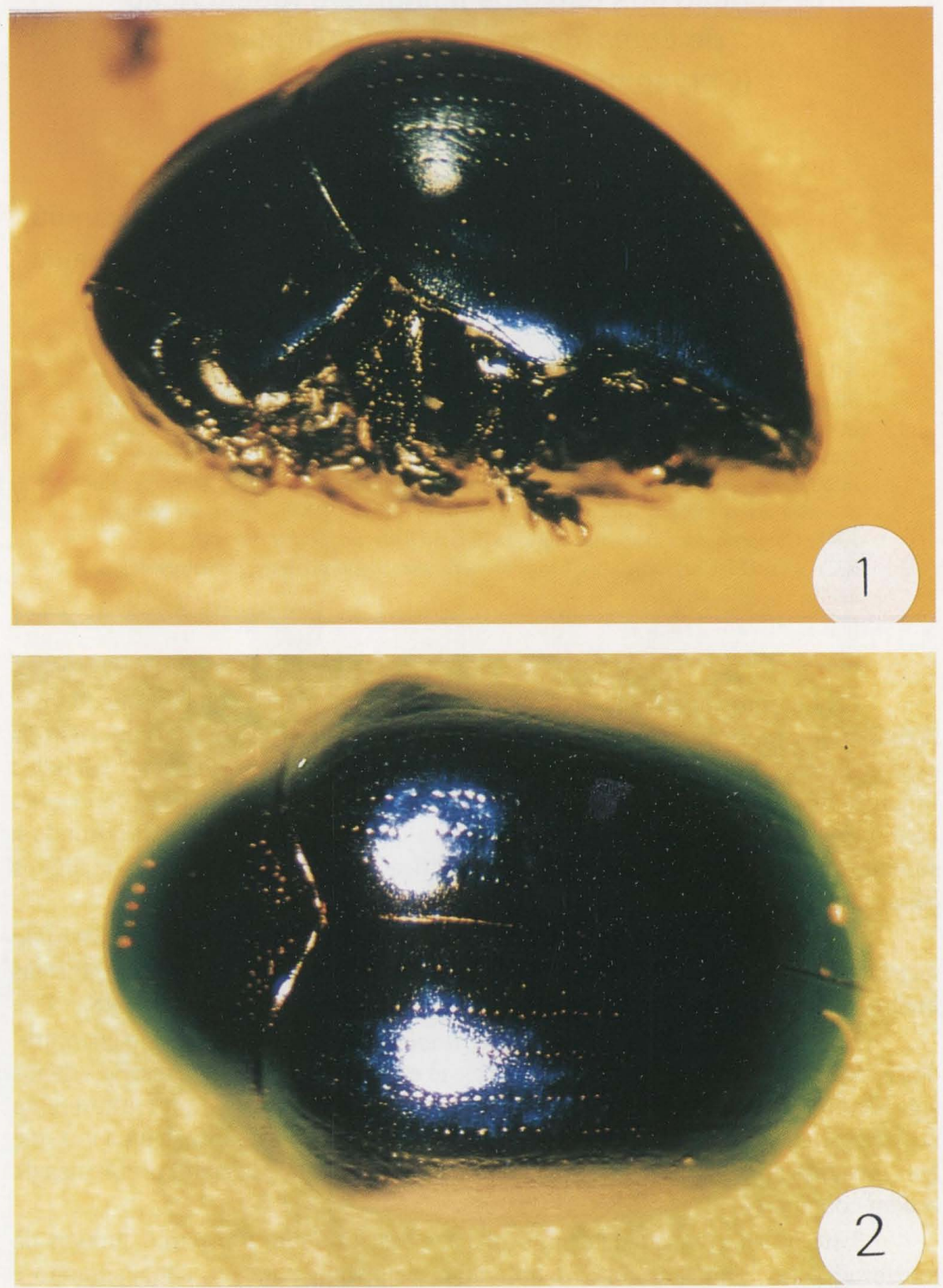

Figs 1-2. Lamprosoma azureum. (1) Vista lateral; (2) vista dorsal.

Revta bras. Zool. 16 (Supl. 1): 243 - 256, 1999 
Os insetos foram coletados manualmente em araçazeiro Psidium cattleianum Sabine, 1821, nos municípios de Colombo, Piraquara e Curitiba, estado do Paraná, durante o período de outubro de 1996 a dezembro de 1997 . O material coletado foi levado ao laboratório para criação em gaiolas de alumínio contendo mudas de araçazeiro das variedades vermelha e amarela.

As formas imaturas foram fixadas em Kahle-Dietrich e os adultos foram montados em alfinetes entomológicos. Os insetos foram dissecados com o auxílio de pinças e estiletes. Os adultos foram fervidos inicialmente em água destilada e sabão, sendo algumas partes fervidas em hidróxido de potássio - $\mathrm{KOH}$ a $10 \%$ para a remoção dos restos de tecidos. Por apresentarem pigmentação negra, algumas peças foram novamente fervidas por alguns minutos em água sanitária comercial pura e conservados em álcool a $70 \%$.

A terminologia adotada para as larvas, foi a utilizada por MOREIRA (1913), ALMEIDA \& RIBEIRO (1986) e LEE \& MORIMOTO (1991). Para o adulto foi adotada a de MonRós (1956) e SUZUKI (1988). Para venação alar e interpretação dos escleritos utilizou-se os trabalhos de SUZUKI (1994).

As fotos foram obtidas em microscópio eletrônico de varredura, do Centro de Microscopia Eletrônica da Universidade Federal do Paraná.

\section{Lamprosoma azureum Germar, 1824}

Macho. Corpo ovalado, superfície dorsal fortemente convexa e ventral plana (Fig. 1). Comprimento do macho variando de $6,67 \mathrm{~mm}$ a $8,17 \mathrm{~mm}$ e maior largura de $5,00 \mathrm{~mm}$ a $6,00 \mathrm{~mm}$. Cabeça, pronoto e élitros azul índigo a azul chumbo (Figs 1,2 ), ou com reflexos verde-metálicos; pernas e abdome de coloração negra. Élitros com dez fileiras de pontos estendendo-se da base até o ápice, onde se fundem. Em vista dorsal, são visíveis apenas oito fileiras. Cada ponto com um curto pêlo (Fig. 3). Pró, meso e metasterno negros. Fronte e pronoto com pontuação fina semelhante.

Cápsula cefálica arredondada, com o comprimento pouco maior que a largura, opistognata (Fig. 5). Olhos compostos bem desenvolvidos, emarginados na altura da inserção das antenas. Antenas (Fig. 6) curtas, com onze artículos, inserção exposta entre a base, o olho e as bordas laterais do clípeo. Escapo aproximadamente quatro vezes mais longo que o pedicelo, ambos de coloração tendendo para o fulvo, com o quarto basal estrangulado externamente; pedicelo quadrangular, terceiro artículo, o menor, este e o quarto completamente encaixados; do quinto ao décimo primeiro artículos com margens externas serreadas. As superfícies externa e interna com pequenos tufos de pêlos curtos. Labro (Fig. 7) curto, quadrangular, quase três vezes mais estreito que o clípeo, bordos laterais arredondados, com pequenas cerdas grossas. Mandíbulas (Fig. 8) bem desenvolvidas, assimétricas, robustas, triangulares, com dois côndilos proeminentes, região apical com um dente incisivo curto, superfície dorsal arredondada. Maxilas (Fig. 9) com cardo alongado, estipe robusto, gálea com ápice arredondado e lacínia com ápice truncado com cerdas espessas; palpo maxilar com cerdas longas e esparsas, último artículo com ápice truncado e superfície densamente revestida por sensilas. Lábio (Fig. 10) com cerdas longas e 
esparsas distribuídas na região da glossa; mento, premento e submento bem diferenciados; palpos labiais triarticulados com o artículo basal reduzido e o artículo apical com a superfície truncada e provida de sensilas.
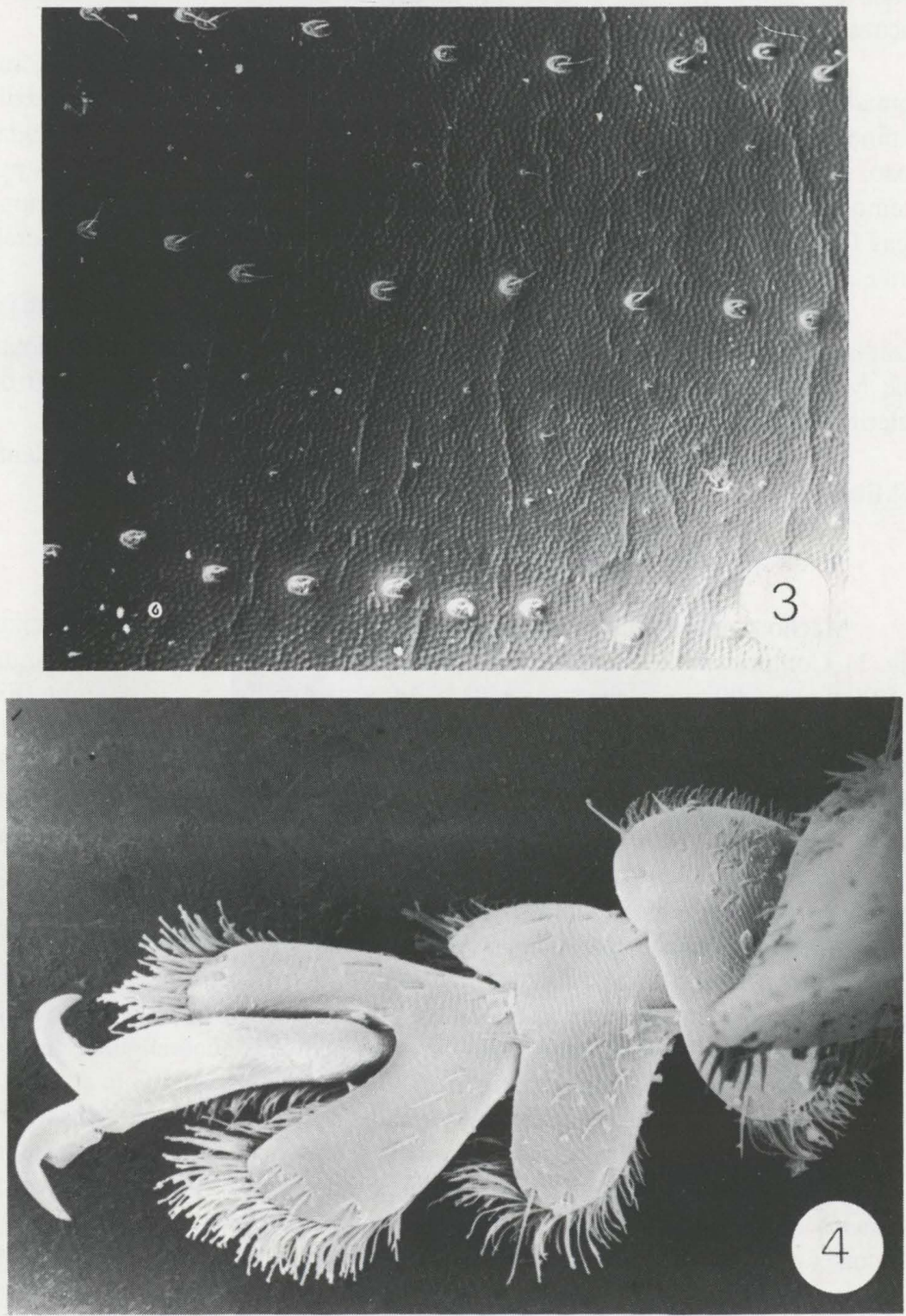

Figs 3-4. Fotomicrografia de varredura de Lamprosoma azureum. (3) Detalhe do élitro; (4) tarsômeros (perna metatorácica). 
Protórax (Figs 1,2) convexo, mais estreito que a base dos élitros, sinuoso na base, com pontuação fina, semelhante à da fronte, na região apical e mais grossa na região basal; processo prosternal truncado no ápice, com comprimento maior que duas vezes sua largura. Meso e metatórax firmemente conectados; mesotórax pequeno, com escutelo triangular. Epipleura estreita, apresentando uma escavação para encaixe do fêmur posterior. Asas membranosas (Fig. 11), com venação reduzida, os três escleritos axilares distintos (1EA, 2EA ẹ 3EA). 1EA articulando-se com a Subcosta, 2EA com a Placa Mediana e 3EA com a base das cubitais e com a área jugal. $\mathrm{Na}$ área distal aparece apenas a marca da venação R2 à R5; r-m representada por uma ponte esclerotinizada; área basal com três células distintas formadas pelas cubitais.

Pernas anteriores (Fig. 12a) com coxa quadrangular, trocanter triangular, pequeno, fêmur desenvolvido com margem interna em forma de dente, tíbia com margem externa angulosa com pequena projeção próxima do ápice; margem interna com área pilosa para encaixe o fêmur e com um esporão apical. Quatro tarsômeros visíveis, primeiro, segundo e terceiro largos e emarginados no ápice, com escova de pêlos na superfície ventral (Figs 12a, 4), quarto tarsômero muito reduzido e o quinto alongado com garra apendiculada. Perna média (Fig. 12b) semelhante à anterior, porém com o fêmur sem projeções internas e o esporão apical interno da tíbia proeminente. Perna posterior (Fig. 12c) com a coxa transversa, tíbia com o ápice alargado e com área interna para o encaixe no fêmur. Abdome com cinco esternos visíveis, o último serrilhado no ápice (aparelho estridulatório) (Fig. 13). Primeiro esterno abdominal visível com depressões laterais em forma de arcos para encaixe dos fêmures posteriores; porção mediana do segundo ao quinto esternito pontuado e com cerdas curtas. Edeago (Fig. 14) simples, robusto, bem esclerotinizado, com tégmen para a sustentação do lobo médio, parte posterior com ápice invaginado.

Fêmea. Com comprimento variando de 7,50 $\mathrm{mm}$ a $9,33 \mathrm{~mm}$ e maior largura de 5,50 a $6,67 \mathrm{~mm}$, semelhante ao macho, exceto pelo fêmur da perna anterior que não apresenta projeção interna. Genitália (Fig. 15) com espermateca simples, em forma de ferradura, bem esclerotinizada, marrom-amarelada; parede da espermateca muito fina, de espessura uniforme. Ducto espermático muito longo, tubular, de largura quase uniforme, em formato de serpentina, esclerotinizado, com a mesma cor da espermateca. Coxitos com base afilada e ápice largo, mais ou menos truncado, com pêlos longos.

\section{Descrição das formas imaturas}

Ovo. Coloração amarela, oblongo, com a base truncada (Fig. 16), 1,48 a 1,52 $\mathrm{mm}$ de comprimento por $0.94 \mathrm{~mm}$ a $1,00 \mathrm{~mm}$ de maior largura. Os ovos são cobertos por uma escatoteca marrom escura (Fig. 27), em forma de sino, com protuberâncias laterais dispostas em linhas longitudinais. Ficam presos à planta hospedeira por uma haste afilada.

Larva. Scarabaeiforme, com corpo em forma de "C" (Figs 16, 18), com 8,17 $\mathrm{mm}$ a $11,50 \mathrm{~mm}$ de comprimento e maior largura variando de $5,67 \mathrm{~mm}$ a $6,83 \mathrm{~mm}$. Coloração da cabeça e pronoto marrom-claros, pernas marrom-escuras, restante do corpo amarelo-claro a escuro. 

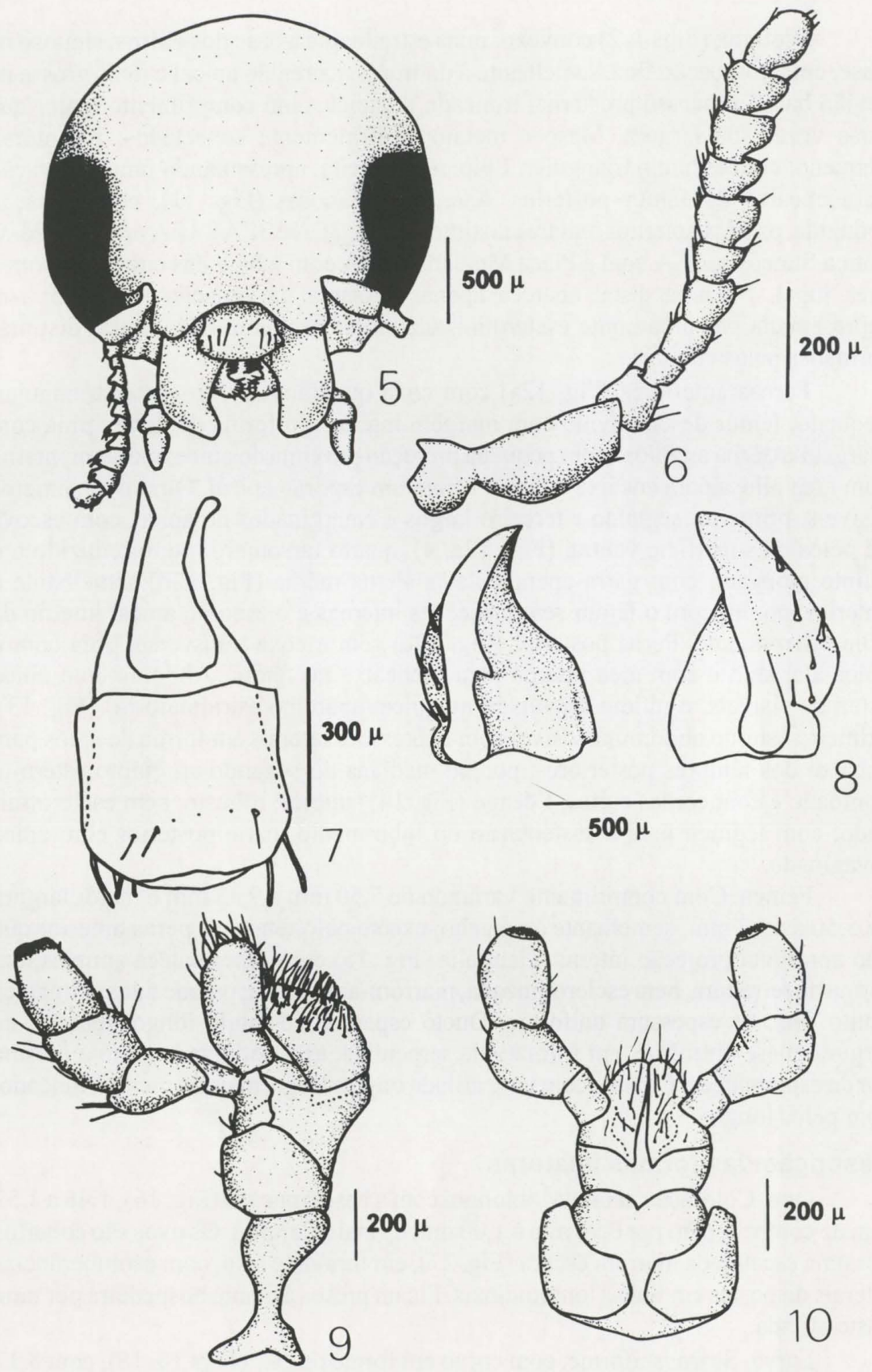

Figs 5-10. Lamprosoma azureum, adulto. (5) Cabeça, frontal; (6) antena; (7) labro; (8) mandíbulas, dorsal, esquerda e direita; (9) maxila; (10) lábio. 

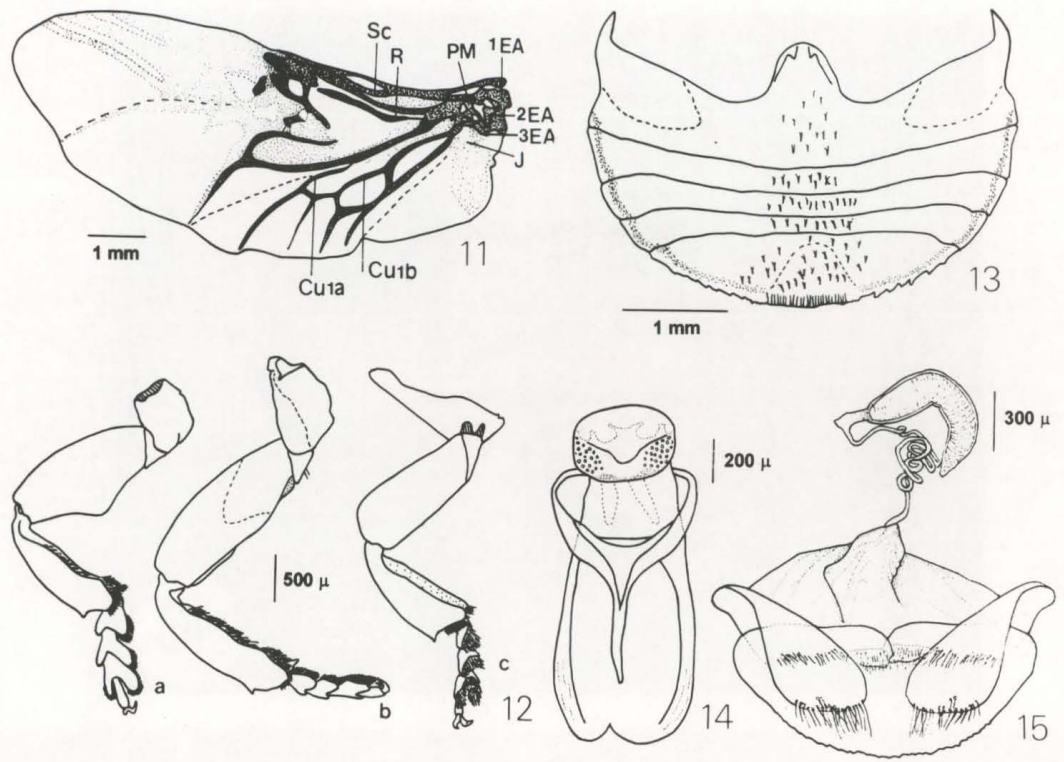

Figs 11-15. Lamprosoma azureum, adulto. (11) Asa membranosa; (12) pernas; (13) abdome; (14) edeago; (15) genitália da fêmea. (a) Anterior, (b) média, (c) posterior, (Cu) cubitais, (EA) escleritos axilares, $(\mathrm{J})$ área jugal, $(\mathrm{PM})$ placa mediana, $(\mathrm{R})$ radial, $(\mathrm{Sc})$ subcosta.

Cabeça hipognata, esclerotinizada, com as bordas arredondadas, sutura epicranial bem marcada em forma de $\mathrm{Y}$ invertido, sutura coronal igual a metade do comprimento da cabeça (Fig. 19). Cerdas esparsas distribuídas por toda a fronte. Cinco estemas, de cada lado, bem desenvolvidos, distribuídos em dois grupos: três anteriores, ao lado da inserção da antena e dois posteriores, abaixo da base da mesma. Epicrânio com quatro pares de sensilas distribuídas paralelamente à sutura coronal, um pouco afastados desta; com numerosas cerdas distribuídas ao longo da cabeça. Antena (Fig. 20) com três artículos distintos, o primeiro mais largo e pouco mais longo que o segundo; este com duas pequenas sensilas localizadas na metade basal; terceiro artículo reduzido com oito sensilas e um apêndice sensorial membranoso cupuliforme no ápice. Fronte, clípeo e labro (Fig. 19) fundidos formando o nasal, com margem apical ondulada. Mandíbula (Fig. 21) robusta, simétrica, sem dentes, sem mola, penicilo e retináculo; superfície ventral com uma borda cortante levemente côncava, superfície dorsal convexa, com duas cerdas mandibulares sobre a borda externa. Maxila (Fig. 23) com estipe longo, com quatro longas cerdas na margem externa e duas cerdas no ápice próximas à mala; esta com onze cerdas apicais, de ápice truncado; cardo alongado com uma cerda. Palpo maxilar com três artículos, o primeiro com um par de sensilas, o segundo com uma sensila e um par de cerdas e o terceiro com uma sensila na metade basal e numerosas no ápice, o palpígero com duas cerdas. Lábio (Fig. 22) com premento e posmento fusionados; posmento com três pares de cerdas; lígula cilíndrica, com três pares de cerdas. Palpo labial com dois artículos; o segundo com mais de duas vezes o tamanho do primeiro, este com uma sensila na porção mediana e numerosas sensilas na região apical. 

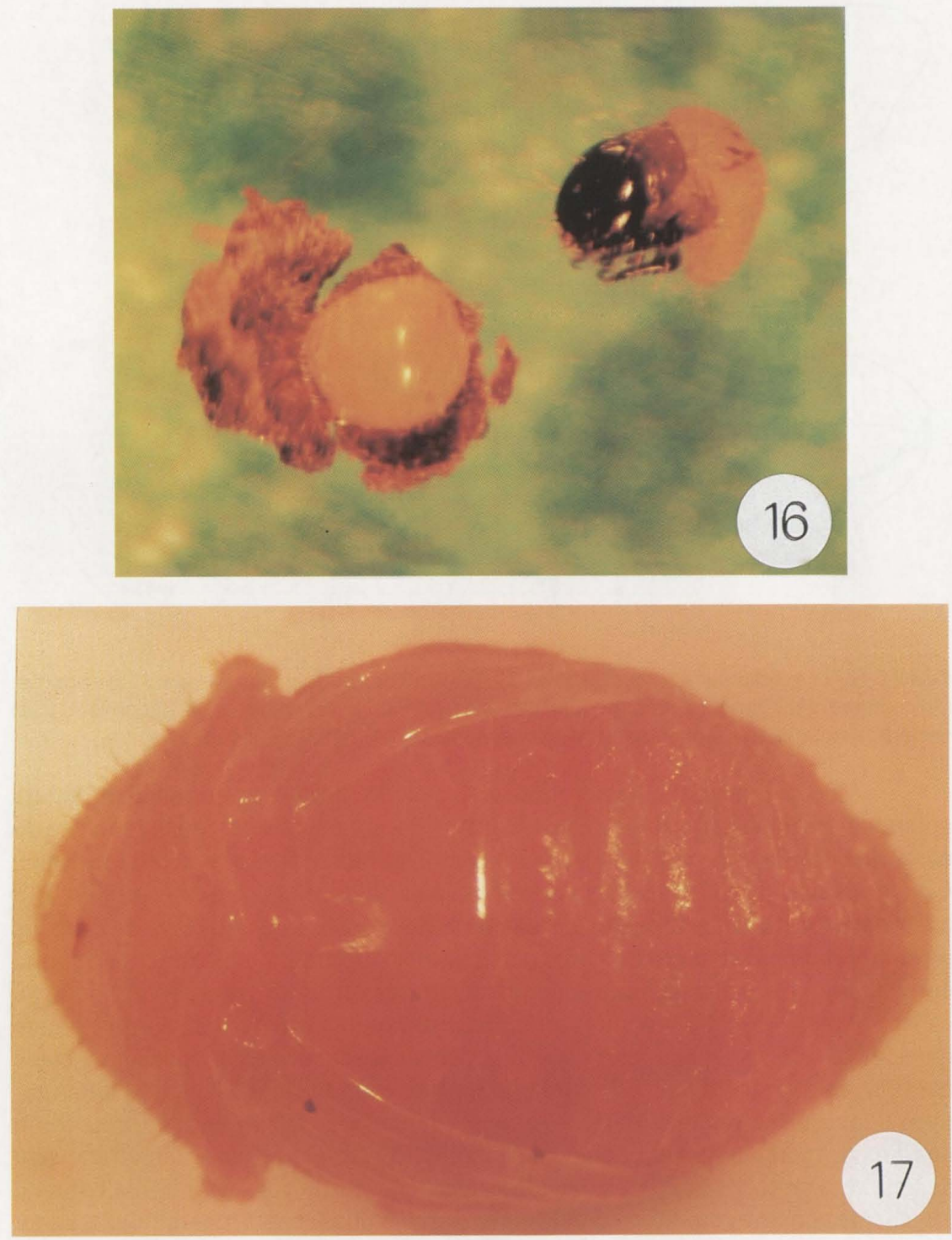

Figs 16-17. Lamprosoma azureum. (16) Ovo e larva recém eclodida; (17) pupa.

Pronoto fracamente esclerotinizado. Meso e metanoto não esclerotinizados. Pernas alongadas e sem pulvilo. Pernas anteriores (Fig. 24), médias e posteriores semelhantes quanto a forma, cor e quetotaxia; coxa com quinze cerdas, trocanter com três cerdas, fêmur com sete cerdas, tíbia com nove cerdas. Tarsúngulo unciforme, com uma cerda na base (Fig. 25). 


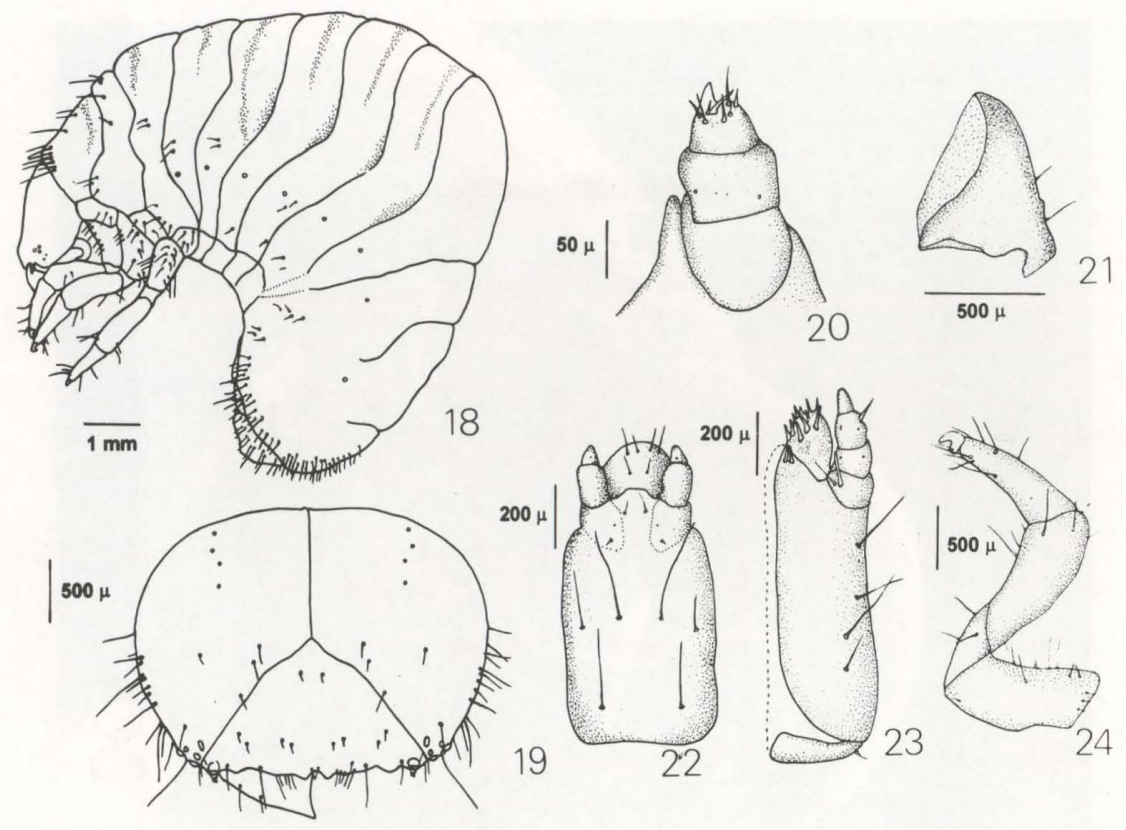

Figs 18-24. Lamprosoma azureum, larva. (18) Quarto instar, lateral; (19) cabeça; (20) antena; (21) mandibula; (22) lábio; (23) maxila; (24) perna anterior.

Abdome curvado para frente, não esclerotinizado. Espiráculos (Fig. 26) presentes nos segmentos 1-8, semelhantes ao espiráculo metatorácico. A parte terminal do abdome dilatada, apresentando numerosas cerdas curtas.

Pupa. Adética e exarata (Fig. 17) com cerca de $8,33 \mathrm{~mm}$ a $11,50 \mathrm{~mm}$ de comprimento e $5,17 \mathrm{~mm}$ a $6,00 \mathrm{~mm}$ de maior largura; coloração de branco-amarelada até alaranjada brilhante. Olhos apenas escurecidos; antenas não protegidas no sulco prosternal, como ocorre no adulto, dispostas livremente; região dorsal do protórax com cerdas eretas. Somitos e membranas perfeitamente distintos; cada élitro com duas fortes franjas longitudinais que convergem na direção da extremidade e correspondem às dez linhas longitudinais dos pontos nos élitros do adulto farado. Pernas metatorácicas escondidas sob as pterotecas.

Escatoteca. Na fase de ovo em formato de sino (Fig. 27), com 2,00 a 2,60 $\mathrm{mm}$ de altura e 2,14 a 2,90 $\mathrm{mm}$ de diâmetro. Com o desenvolvimento larval, ocorre deposição de material, atingindo forma semelhante a de um acúleo de roseira (Fig. 28), com comprimento de 15,00 a $20,00 \mathrm{~mm}, 7,33$ a $10,17 \mathrm{~mm}$ no maior diâmetro e 10,00 a $14,67 \mathrm{~mm}$ de altura. No último ínstar, a escatoteca apresenta uma separação, o ápice é utilizado pela larva apenas nos primeiros instares e na base há um espaço maior onde a larva de último ínstar se aloja. Coloração marrom-escura a marrom-acinzentada, de acordo com a coloração da casca do hospedeiro, com um largo sulco côncavo que vai da base ao ápice do lado convexo. 

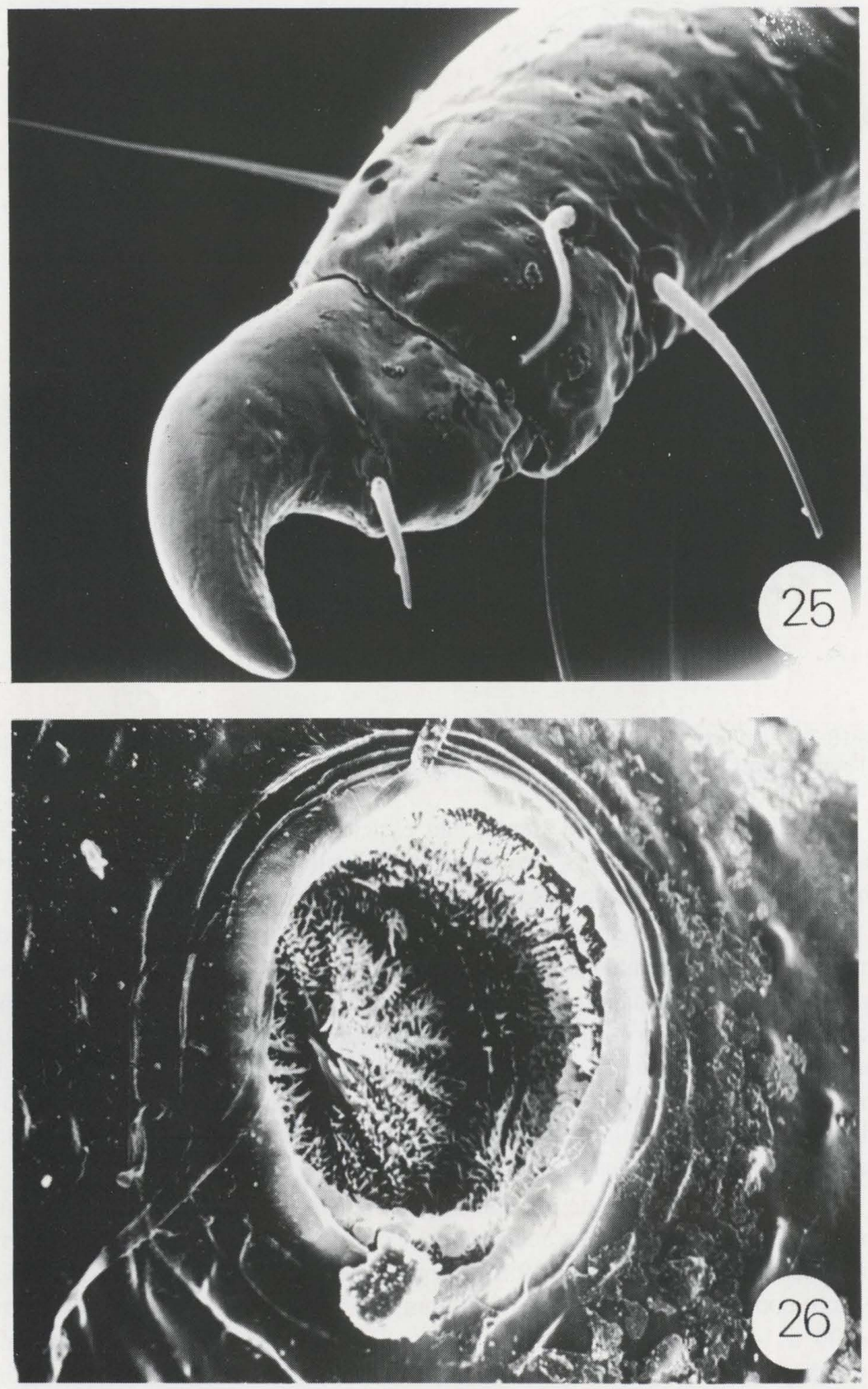

Figs 25-26. Fotomicrografia de varredura de Lamprosoma azureum, larva. (25) Tarsúngulo; (26) espiráculo abdominal. 


\section{DISCUSSÃO}

$\mathrm{O}$ adulto de $L$. azureum é bastante semelhante ao de $L$. dissectum Monrós, 1948 cuja localidade-tipo é Curitiba. A descrição do adulto de $L$. dissectum tem, como características peculiares o formato da placa prosternal, que se assemelha muito àquela de $L$. azureum, a forma ovalada, além da coloração semelhante MONRós (1948).

MONRós (1949) afirma que existem diferenças de coloração entre exemplares de $L$. chorisiae coletados em diferentes localidades, semelhante ao que foi observado em $L$. azureum que além da coloração típica azul-índigo a azul-chumbo, apresenta alguns indivíduos com reflexos esverdeados metálicos. MonRós (1956) em revisão dos gêneros de Lamprosomatinae, reconhece que se o material-tipo das espécies de Lamprosoma fosse estudado, muitas espécies poderiam ser sinonimizadas.

Os trabalhos mais completos, tanto de adultos como de formas imaturas neste grupo de Chrysomelidae se referem ao gênero Oomorphoides. Algumas poucas observações foram feitas a respeito das espécies de Lamprosoma, as principais foram tratadas nos trabalhos de MoREIRA (1913) sobre morfologia de imaturos de L. bicolor e o de MonRós (1949) sobre morfologia de imaturos e aspectos da biologia de L. chorisiae.

Com relação à venação alar, a mesma é semelhante àquela de Oomorphoides nigrocoeruleus Baly, 1873 demonstrada por SUZUKI (1994), diferindo fundamentalmente nos seguintes aspectos: presença de uma seção da veia r-m em $L$. azureum e apenas os contornos da mesma em $O$. nigrocoeruleus; presença de uma pequena área esclerotinizada próxima à área do pterostigma; Cula e Culb com dois ramos em L. azureum e ambas com apenas um ramo em $O$. nigrocoeruleus.

O ovo de $L$. azureum possui coloração amarela, diferentemente do que foi citado por LEE \& MORIMOTO (1991) para Oomorphoides cupreatus Baly, que apresenta o ovo de coloração marrom, no formato de uma "bolota-de-carvalho", com a superfície formada por protuberâncias dispostas em linhas oblíquas. No entanto, é pedunculado como o de L. azureum. A descrição dos autores citados parece estar relacionada à escatoteca parental dos Lamprosomatinae e não ao ovo propriamente dito, uma vez que a escatoteca parental para $L$. azureum é marrom, em forma de sino com protuberâncias laterais dispostas em linhas, guardando semelhança com a descrição do ovo de $O$. cupreatus.

A larva de L. azureum se assemelha às larvas de L. bicolor (MOREIRA 1913) e L. chorisiae (MonRós 1949), na coloração, forma do corpo e tamanho. Existem algumas diferenças entre as três larvas: a antena de $L$. azureum possui três artículos, o que também é verificado em $L$. bicolor, sendo diferente para $L$. chorisiae que possui dois artículos. As larvas de Oomorphoides cupreatus (LEE \& MORIMOTO 1991) apresentam a forma do corpo semelhante, o número de estemas e de artículos da antena iguais às de L. azureum. Em Oomorphoides cupreatus a antena é muito maior, porém com número de cerdas menor. A mandíbula é mais robusta em $L$. azureum e não apresenta dente apical. Outra característica evidente que diferencia L. azureum é o segmento terminal do abdome que é coberto de cerdas, enquanto que em Oomorphoides cupreatus é praticamente glabro. 

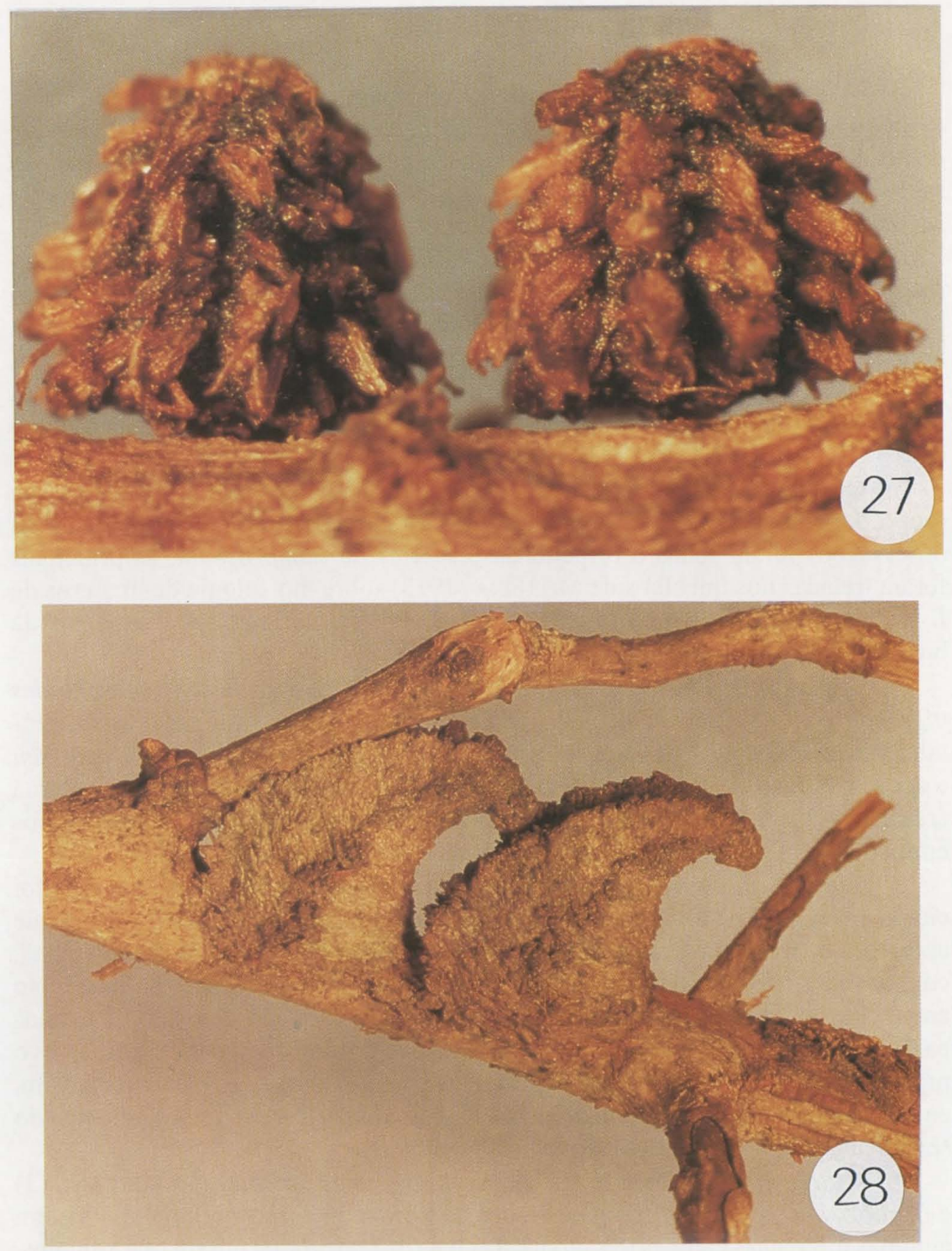

Figs 27-28. Lamprosoma azureum, escatoteca. (27) Do ovo; (28) da larva de quarto instar.

A pupa de $L$. azureum é menor em comprimento que a de Lamprosoma bicolor descrita por MOREIRA (1913); é maior que a de L. chorisiae, descrita por MonRós (1949). Assemelha-se à descrição de ambas, porém, difere de L. chorisae por não apresentar a forquilha levemente esclerotinizada no extremo abdominal. 
A escatoteca de $L$. azureum se parece bastante em forma e tamanho com aquela descrita por MOREIRA (1913) para L. bicolor, que por sua vez, está de acordo com as observações de LINSENMAIER (1972) que afirma que a escatoteca dos Lamprosoma é constituída de madeira e casca, que a larva adiciona de acordo com seu crescimento. LAWSON (1991) cita que alguns Chrysomelidae, dentre eles os Lamprosomatinae, produzem "ootecas" que podem ser compostas de fezes (escatotecas), secreções glandulares do coleterium ou ambas. Foi constatada que a escatoteca construída pela fêmea de $L$. azureum para proteção do ovo é formada por fezes e casca do hospedeiro.

Foi observado em L. azureum, que de acordo com o hospedeiro, a escatoteca adquire coloração semelhante à da casca, denotando que a mesma é constituída de fragmentos da casca aglutinados com os excrementos da larva. Essas observações estão de acordo com as dos autores anteriormente citados, divergindo unicamente de MonRós (1949) para L. chorisiae, que afirma que as escatotecas desta espécie parecem ser constituídas apenas de substâncias digeridas pela larva. Além disso a forma da escatoteca de $L$. chorisiae é mais ou menos fusiforme e de seção quase circular, diferindo das apresentadas por L. azureum e L.bicolor.

AGRADECIMENTOS. Ao biólogo Carlos Campaner, Museu de Zoologia, Universidade de São Paulo pela identificação do material entomológico. À Prof. Dra. Daura Regina Eiras-Stofella, Universidade Federal do Paraná pelas fotos de microscopia eletrônica.

\section{REFERÊNCIAS BIBLIOGRÁFICAS}

ALMEIDA, L.M \& C.S. RiBeIRO. 1986. Morfologia dos estágios imaturos de Epilachna cacica Guérin, 1844 (Coleoptera, Coccinelidae). Revta bras. Ent. 30 (1): 43-49.

ChapuIs, F. 1874. Coléoptères. Famille Des Phytophages, p.212-220. In: T. LACORDAIRE \& F. CHAPUIS (Eds). Genera des Coléoptères ou exposé méthodique et critique de tous les generes proposés jusqu'ici dans cet ordre d'insectes. Paris, Librairie Encyclopédique de Roret, Vol. 10, 455p.

GERMAR, E.F. 1824. Insectorum species novae aut minus cognitae descriptionibus illustratae. Halae, 624p.

Lawson, F.A. 1991. Chrysomelidae (Chrysomeloidea) (=Cassididae, Cryptocephalidae, Megalopodidae, Sagridae, etc.), p.568-585. In: F. STEHR (Ed.). Immature insects. Dubuque, Kendall Hunt Publishing Co., Vol. 2, 754p.

LEE, J.E. \& K. MoRIMOTO. 1991. The egg and first-instar larva of Oomorphoides cupreatus (Baly) from Japan, with notes on the systematic position of Lamprosomatinae (Coleoptera: Chrysomelidae). Jour. Fac. Agr., Kyushu Univ., 35 (3/4): 101-107.

LINSENMAIER, W. 1972. Insects of the world. New York, McGraw-Hill, 392p.

MonRós, F. 1948. Descripción de diez nuevas espécies de Lamprosoma neotropicales (Col. Chrysomelidae). Acta zool. lilloana 5: 81-95.

- 1949. Descripción de la metamorfosis de Lamprosoma chorisiae Monrós y consideraciones taxonómicas sobre "Lamprosominae" (Col. Chrysomelidae). 
Acta zool. lilloana 7: 449-466.

1956. Revisión Genérica de Lamprosominae con descripción de algunos generos y espécies nuevas (Col. Chrysomelidae). Revta Agron. Noroeste Argentino 2: 25-77.

12: $29-33$.

1958. Notes on Lamprosomatinae. (Chrysomelidae). Coleopterists Bull.

1960. Coleopterorum Catalogus. 53. Chrysomelidae: Lamprosomatinae. Suppl. Berlim Junk, Vol. 10, p.1-16.

Moreira, C. 1913. Metamorphoses de quelques coleóptères de Brésil. Ann. Soc. ent. Fr. 84: 743-751.

SUZUKI, K. 1988. Comparative morphology of the internal reproductive system of the Chrysomelidae (Coleoptera), p.318-355. In: P.H. JOLIVET; E. PETITPIERRE \& T.H. HSIAO. Biology of Chrysomelidae. Dordrecht, Kluwer, 615p.

1994. Comparative morphology of the hindwing venation of Chrysomelidae (Coleoptera), p.337-354. In: P.H. Jolivet; M.L. Cox \& E. PeTITPIERRE (Eds). Novel aspects of the biology of Chrysomelidae. Dordrecht, Kluwer, $582 \mathrm{p}$.

Recebido em 26.XI.1998; aceito em 31.V.1999. 